\title{
Structural Heterogeneity and Environmentally Regulated Remodeling of Francisella tularensis subspecies novicida Lipid A Characterized by Tandem Mass Spectrometry
}

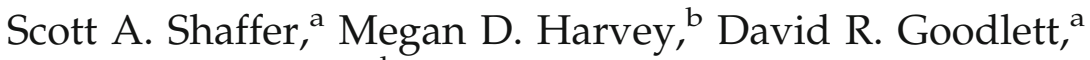 \\ and Robert K. Ernst $\mathrm{t}^{\mathrm{b}}$ \\ ${ }^{a}$ Department of Medicinal Chemistry, University of Washington, Seattle, Washington, USA \\ ${ }^{\mathrm{b}}$ Department of Medicine, University of Washington, Seattle, Washington, USA
}

\begin{abstract}
The structural characterization of environmentally-regulated lipid A derived from Francisella tularensis subspecies novicida (Fn) U112 is described using negative electrospray ionization with a linear ion trap Fourier transform ion cyclotron resonance (IT-FT-ICR) hybrid mass spectrometer. The results indicate that a unique profile of lipid A molecular structures are synthesized in response to Fn growth at $25^{\circ} \mathrm{C}$ versus $37^{\circ} \mathrm{C}$. Molecular species were found to be tetra-acylated, sharing a conserved glucosamine disaccharide backbone, a galactosamine1-phosphate linked to the reducing glucosamine, and multiple O- and N-linked fatty acyl groups. Deprotonated molecules were interrogated by $\mathrm{MS}^{n}$ scanning techniques at both high and nominal mass resolution and were found to be complex heterogeneous mixtures where structures differed based on the positions and identities of the O- and N-linked fatty acyl substituents. For the dominant ion series, which consisted of five peaks, 30 unique lipid A structures were identified. Estimates for the relative abundance of each structure were derived from MS relative abundance ratios and fragment ion ratios from comparable dissociation pathways from $\mathrm{MS}^{2}$ through $\mathrm{MS}^{4}$ experiments. The results suggest a remodeling pathway in which the amide linked fatty acid of the reducing glucosamine favors a 3-hydroxyhexadecanoic acid substituent for growth conditions at $25^{\circ} \mathrm{C}$ versus a 3-hydroxyoctadecanoic acid substituent for growth conditions at $37^{\circ} \mathrm{C}$. (J Am Soc Mass Spectrom 2007, 18, 1080-1092) () 2007 American Society for Mass Spectrometry
\end{abstract}

$\mathrm{B}$ acterial pathogens have evolved adaptive responses to environmental changes upon entering a host. These responses include remodeling of the bacterial outer membrane, which can alter the bacteria's ability to cause disease or interact with the host's innate immune defenses. Membrane remodeling is accomplished in a variety of ways and has been shown to play a role in virulence [1-3]. The cell envelope of gramnegative bacteria consists of two lipid bilayers: a symmetrical inner membrane composed primarily of phospholipids and an asymmetrical outer membrane containing primarily phospholipids in the inner leaflet and lipopolysaccharide (LPS) in the outer leaflet. Lipid A, also know as endotoxin, is the hydrophobic membrane anchor of LPS [4, 5]. Tight packing of lipid A in the outer leaflet of the outer membrane creates a permeability barrier against environmental compounds and antimicrobial components of the host innate im-

Address reprint requests to Dr. R. K. Ernst, Department of Medicine, University of Washington, Health Sciences Building, Box 357710, 1959 Pacific St. N.E., Seattle, WA 98195, USA. E-mail: rkernst@u.washington.edu, and to Dr. D. R. Goodlett, Department of Medicinal Chemistry, University of Washington, Health Sciences Building, Box 357610, 1959 Pacific St. N.E., Seattle, WA 98195, USA. E-mail: goodlett@u.washington.edu mune system [6]. Specific alteration of lipid A structure, including changes to the carbohydrate and fatty acid composition, can occur via a variety of environmental stimuli including divalent ion concentration, temperature, and other growth conditions [1, 7-10].

Francisella tularensis subspecies tularensis $(\mathrm{Ft})$ is a highly infectious, gram-negative pathogen, and is the causative agent of tularemia in humans [11-13]. Human tularemia can occur in several forms depending on the route of entry, but in most cases is the result of a bite by an infected arthropod or inhalation of contaminated aerosols. Ft has been designated as a Class A select agent by the Centers for Disease Control and Prevention due to its potential use as a bioterrorism agent. The genus Francisella tularensis consists of four subspecies: tularensis (Type A), holartica (Type B), mediasiatica, and novicida. In humans, subspecies novicida (Fn) is only infectious in immunocompromised individuals [14]. However, in mice, both Ft and Fn cause a tularemia-like disease [15]. Previously, the structure of lipid A isolated from two type B Francisella tularensis subspecies holartica strains (1547-57 and LVS) after growth at $37^{\circ} \mathrm{C}$ were elucidated using mass spectrometry, gas chromatography, and chemical methods [16, 17]. The base lipid A 
structure for both strains was similar and consisted of a $\beta$-1,6-linked diglucosamine disaccharide with a single phosphate moiety at the 1 position, amide-linked fatty acids at the 2 and $2^{\prime}$ positions, and ester-linked fatty acids at the 3 , but not the $3^{\prime}$, positions. Interestingly, in the 1547-57 strain, the 1-phosphate moiety was determined to be substituted with galactosamine and defined a unique bacterial lipid A structure [16]. In studies of both strains, only the primary structures represented by the base peaks in the mass spectra were elucidated. In addition, matrix assisted laser desorption ionizationtime of flight (MALDI-TOF) mass spectrometry (MS) of lipid A isolated from clinical and environmental strains of F. tularensis subspecies tularensis, holartica, and mediasiatica after growth in rich medium at $37^{\circ} \mathrm{C}$ were similar, and suggests a common lipid A structure for all F. tularensis subspecies [18].

The use of mass spectrometry for the structure elucidation of intact lipid A has been approached by both positive and negative ionization methods using fast atom bombardment [19-22], matrix-assisted laser desorption [23-25], and electrospray [26-29]. While these techniques often lead to complementary data, negative ionization is often necessary for acyl chain identification where collision induced dissociation (CID) of deprotonated molecules results in the observation of fatty acyl carboxylate anions [27, 28]. On quadrupoles, sectors, or time-of-flight instruments, these types of ions are readily observed, but on ion traps they are typically lost due to the low $\mathrm{m} / \mathrm{z}$ cut-off imposed by the " $\mathrm{Q}$ " value of the ion trap and have to be inferred from parent ion neutral losses [30, 31]. More importantly, however, ion traps offer the advantage of multiple stages of CID (i.e., $\mathrm{MS}^{n}$ ) and provide a means to deconvolute and map the unimolecular fragmentation pathways for a given parent ion. With the advent of linear ion traps, this can be done with great sensitivity due to the increased ion storage capacity and dual electron multipliers found in the linear ion trap compared with previous three dimensional ion trap designs [32].

In this study, we report that lipid A isolated from Francisella tularensis subspecies novicida (Fn), strain $\mathrm{U} 112$, is a complex heterogeneous mixture of structures that display a unique abundance profile in response to a change in growth temperature (i.e., $25^{\circ} \mathrm{C}$ versus $37^{\circ} \mathrm{C}$ ). This analysis was carried out using negative electrospray ionization (ESI) coupled to a linear ion trap (LTQ)-Fourier transform ion cyclotron resonance (FTICR) hybrid mass spectrometer (i.e., Thermo LTQ-FT). The approach utilized a combined advantage over previous methodologies: accurate mass measurement of deprotonated molecules and MS/MS fragments, the use of automatic gain control (AGC) that served to normalize the dynamic range between ions selected for MS/MS, and the use of MS and MS $^{n}$ fragment ion relative intensities to derive estimates for the relative abundance of each molecular species. The data indicate that the deprotonated molecules are heterogeneous mixtures, which differ as to the identities of the $\mathrm{N}$ - and O-linked fatty acyl substituents on the diglucosamine core. Further, analysis of the data support a membrane remodeling pathway in which the majority of lipid A structures from Fn grown at different temperatures results in alterations of the fatty acids linked to the diglucosamine core. In other gram-negative pathogens, temperature change induces expression of genes essential to their life cycle, such as transition between their natural reservoirs (e.g., arthropod to mammal) [33, 34]. Therefore, alteration of lipid A structure upon entry into the mammalian host may represent a pathogenesis strategy common to the Francisella species.

\section{Experimental}

\section{Bacterial Strains and Growth Conditions}

Francisella tularensis subspecies novicida strain U112, obtained from Francis Nano (University of Victoria, Victoria, Canada) was grown in tryptic soy broth (Gibco BRL, Grand Island, NY) supplemented with $0.1 \%$ cysteine (TSB-C; Sigma-Aldrich, St. Louis, MO) at $25{ }^{\circ} \mathrm{C}$ or $37^{\circ} \mathrm{C}$ with aeration and harvested in the stationary phase.

\section{LPS Purification and Lipid A Isolation}

Fn LPS was extracted using a hot phenol/water extraction method [35]. Subsequently, LPS was treated with RNase A, DNase I, and proteinase $\mathrm{K}$ to ensure purity from contaminating nucleic acids and proteins [36]. Lipid A was isolated after hydrolysis in 1\% SDS at pH 4.5 as described [37]. The yield of LPS was 0.9 to $10 \mathrm{mg}$ dry cells.

\section{Fatty Acid Analysis}

LPS fatty acids were determined after conversion to methyl esters as previously described by methanolysis in $2 \mathrm{M}$ methanolic $\mathrm{HCl}$ at $90^{\circ} \mathrm{C}$ for $18 \mathrm{~h}$ [38, 39].

\section{Electrospray Ionization IT-FT-ICR Mass Spectrometry}

Lipid A was analyzed by electrospray ionization in the negative ion mode on an LTQ-FT linear ion trap Fourier transform ion cyclotron resonance mass spectrometer (Thermo Electron Corp., San Jose, CA). Samples were diluted to $\sim 0.3$ to $1.0 \mathrm{mg} / \mathrm{mL}$ in chloroform/methanol (1:1) and infused using a syringe pump (Harvard Apparatus, Holliston, MA) at 0.5 to $1.0 \mu \mathrm{L} / \mathrm{min}$ via a fused silica capillary (75 $\mu \mathrm{m}$ i.d./360 $\mu \mathrm{m}$ o.d.) with a $\sim 15 \mu \mathrm{m}$ spray tip (New Objective, Woburn, MA). The electrospray voltage was applied via liquid junction using a gold wire inserted into a micro-tee union (Upchurch Scientific, Oak Harbor, WA). Ion source conditions were as follows (voltages are negative): ESI voltage, 1.4 to $1.8 \mathrm{kV}$; capillary temperature, 400 to $450{ }^{\circ} \mathrm{C}$, capillary 


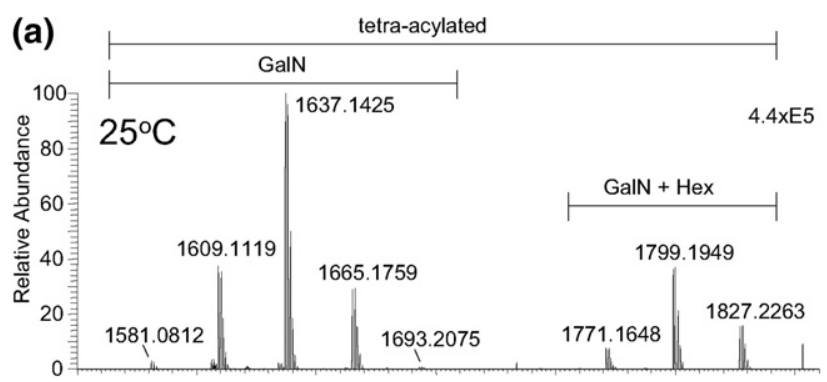

(b)

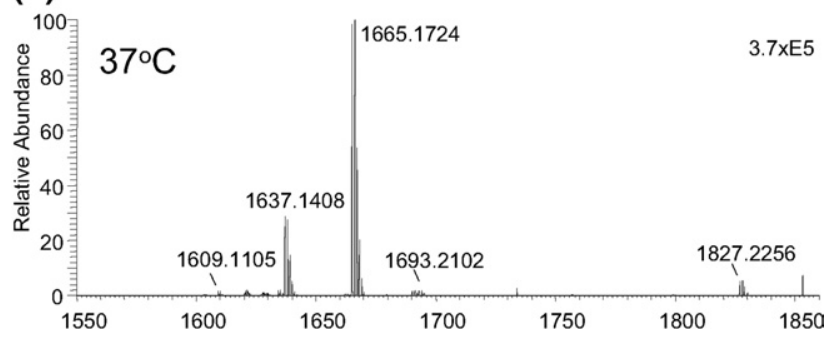

Figure 1. Negative ion FT-ICR MS of Lipid A derived from Fn U112 grown at: (a) $25^{\circ} \mathrm{C}$; (b) $37^{\circ} \mathrm{C}$. The peak found at $\mathrm{m} / \mathrm{z} 1853$ arises from high-frequency noise.

voltage, 16 to $44 \mathrm{~V}$, and tube lens voltage, 200 to $220 \mathrm{~V}$. Instrument calibration and all other tuning parameters were optimized using a solution of Ultramark 1621 (Lancaster Pharmaceuticals, PA).

Injection waveforms for the LTQ-FT linear ion trap and ICR cell were kept on for all acquisitions. For experiments analyzed in the ICR cell, resolution was set to $1.0 \mathbf{e}^{5}(\mathrm{~m} / \mathrm{z} 400)$ and ion populations were held constant by automatic gain control (AGC) at $1.0 \mathrm{e}^{6}$ and $5.0 \mathrm{e}^{5}$ for MS and MS/MS, respectively. The maximum ion fill time for the ICR cell was set to $3 \mathrm{~s}$. For MS/MS, the precursor ion selection window was set to 4 to $8 \mathrm{Da}$ and the collision energy was set to $30 \%$. Spectra were acquired over a 1 to $5 \mathrm{~min}$ period and averaged (typically, 30 to 150 scans depending on conditions). Measured mass accuracies following external calibration were typically ${ }^{+} 5 \mathrm{ppm}$. For $\mathrm{MS}^{n}$ analysis in the linear ion trap, mass spectra were acquired using an ion population of $1.0 \mathrm{e}^{4}$ and a maximum ion fill time of 200 ms. The precursor ion selection window was set to 4 to $8 \mathrm{Da}$ for $\mathrm{MS}^{2}$ and $2 \mathrm{Da}$ for subsequent $\mathrm{MS}^{3}$ and $\mathrm{MS}^{4}$ events. The collision energy was set to $30 \%$ for $\mathrm{MS}^{2}$ and $25 \%$ for $\mathrm{MS}^{3}$ and $\mathrm{MS}^{4}$. For manual $\mathrm{MS}^{n}$ acquisition, multiple scans were averaged with acquisition times of 1 to $2 \mathrm{~min}$. For automated $\mathrm{MS}^{3}$ spectra using data dependent analysis of $\mathrm{MS}^{2}$ precursor ions, 20 scans were averaged for each spectrum. Data were acquired and processed using Xcalibur, Version 1.4 (Thermo) utilizing 7 point Gaussian smoothing.

\section{Results and Discussion}

The negative electrospray ionization (ESI) Fourier transform ion cyclotron resonance (FT-ICR) mass spectra for LPS derived lipid A from Francisella tularensis subspe- cies novicida strain U112 (Fn) are shown in Figure 1. Dramatic shifts in the relative abundance of the major peaks (i.e., deprotonated molecules) are observed between the spectra for growth at $25^{\circ} \mathrm{C}$ (Figure 1a) versus $37^{\circ} \mathrm{C}$ (Figure $1 \mathrm{~b}$ ). The major ions for lipid $\mathrm{A}$ isolated after growth at $25{ }^{\circ} \mathrm{C}$ are found at nominal $\mathrm{m} / \mathrm{z}$ values of 1609, 1637 (base), and 1665, with minor ions at $m / z 1581$ and 1693. A second set of ions arise at $m / z 1771,1799$, and 1827 , corresponding to a shift of $162.0 \mathrm{Da}$ from the dominant ion series and indicate the presence of a hexose group $\left(\mathrm{C}_{6} \mathrm{H}_{12} \mathrm{O}_{6}\right)$. For $\mathrm{Fn}$ grown at $37^{\circ} \mathrm{C}$, the major peaks are found at $m / z$ 1637, 1665 (base), and 1827. Ions at $m / z 1609$ and 1799 are greatly reduced and ions at $m / z 1581$ and 1771 are absent. Comparison of the matrix-assisted laser desorption ionization time-offlight (MALDI-TOF) mass spectra to that produced by ESI was consistent (see Supplementary Material section which can be found in the online version of this article), resulting in the observation of the same ion series with similar relative abundances to that shown in Figure 1.

Fatty acid analysis by gas chromatography with flame-ionization detection was used to confirm the fatty acids present in the LPS derived lipid A samples. Results indicate that the major fatty acids were 3-hydroxyhexadecanoic acid [(16:0)-3-OH], 3-hydroxyoctadecanoic acid [(18:0)-3-OH], tetradecanoic acid (14:0), hexadecanoic acid (16:0), and octadecanoic acid (18:0) (data not shown). Several other minor species were also observed that were not readily identified with the standard mixture used.

\section{Characterization of the Base Peak at m/z 1665 Isolated After Growth at $37{ }^{\circ} \mathrm{C}$}

Lipid A structures were elucidated by linear ion trap tandem mass spectrometry with analysis of the fragment ions in either the ICR cell or linear ion trap. The base peak measured at $\mathrm{m} / \mathrm{z} 1665.1724$ (FT-ICR) from lipid A isolated from Fn grown at $37^{\circ} \mathrm{C}$ (Figure 1b) had the same nominal mass and was determined to be the same structure to that reported for lipid A from Francisella ${ }^{\circ}$ tularensis ${ }^{\circ}$ subspecies holartica ${ }^{\circ}$ strain 1547-57 [16]. While we determined this peak to be a single lipid A structure, other peaks in the mass spectrum were determined to be isobaric mixtures of lipid A structures as described below. Thus, fragmentation described for $\mathrm{m} / \mathrm{z}$ 1665 demonstrates the dissociation processes for a single lipid A entity and also serves to facilitate a method for the deconvolution of other lipid A structures found in the other peaks.

CID of $m / z 1665$ in the linear ion trap, followed by subsequent detection of the fragments in the ICR, gave rise to multiple fragmentation pathways illustrated in Scheme 1 and shown in Figure 2a. Primary dissociations of $\mathrm{m} / \mathrm{z} 1665.1724(-0.5 \mathrm{ppm})$, structure $\mathbf{A}$, consist of neutral loss of $\mathrm{H}_{2} \mathrm{O}(\mathrm{m} / \mathrm{z} 1647.1594 ;-2.1 \mathrm{ppm} ; \mathbf{A 1})$, hexosamine $\left(\mathrm{m} / \mathrm{z}\right.$ 1504.1031; -0.9 ppm; A2), $\mathrm{C}_{16} \mathrm{H}_{32} \mathrm{O}$ $(\mathrm{m} / \mathrm{z}$ 1424.9286; $0.4 \mathrm{ppm} ; \mathbf{A 3})$, palmitic acid $(\mathrm{m} / \mathrm{z}$ 


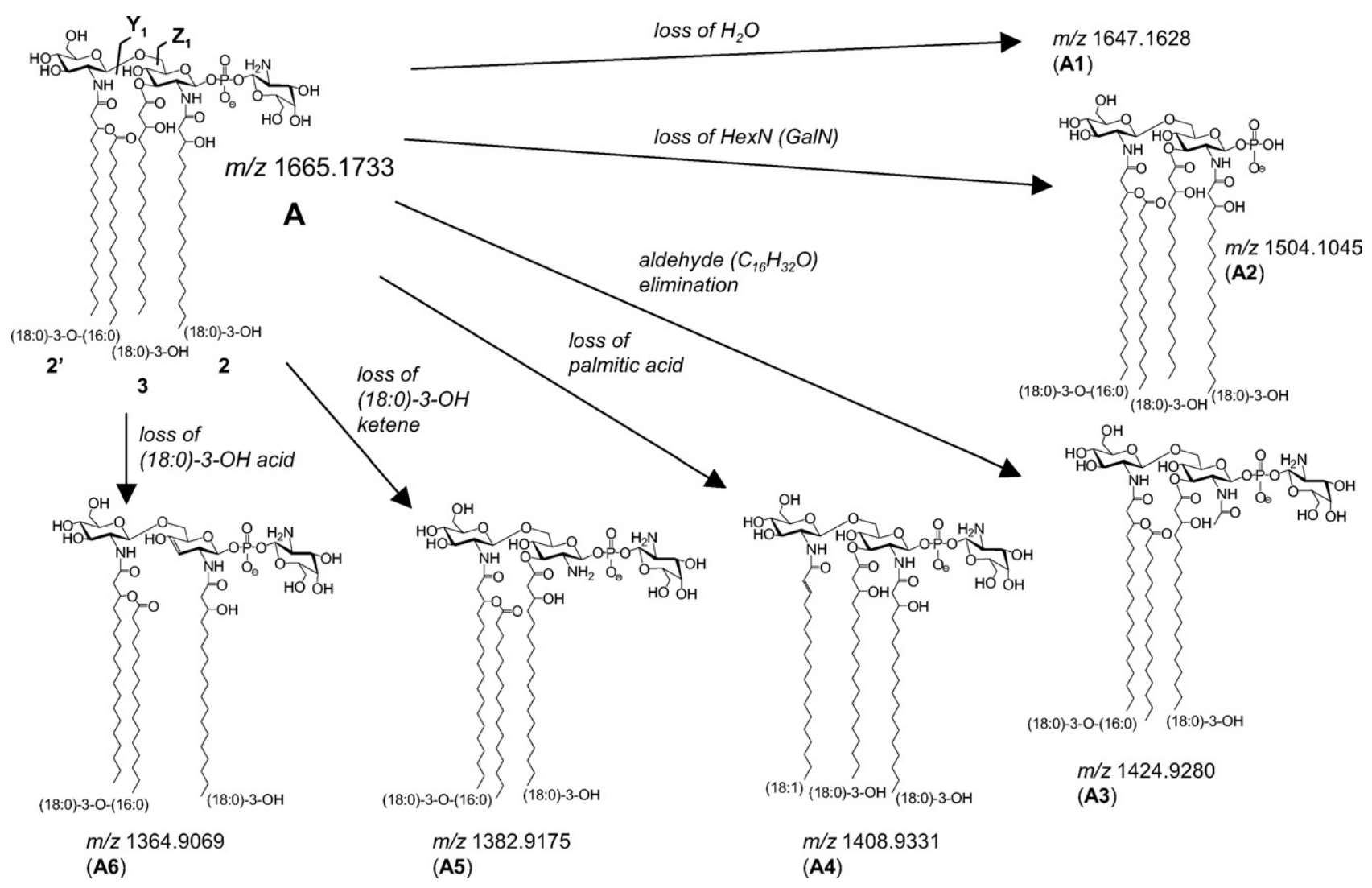

Scheme 1. Primary dissociations of $m / z 1665$ (monoisotopic $m / z$ values given).

1408.9344; 0.9 ppm; A4), (18:0)-3-OH ketene $(\mathrm{m} / \mathrm{z}$ 1382.9176; $0.1 \mathrm{ppm} ; \mathbf{A} 5)$, and (18:0)-3-OH fatty acid $(\mathrm{m} / \mathrm{z}$ $1364.9065 ;-0.3 \mathrm{ppm} ; \mathrm{A6})$. The loss of the hexosamine (HexN) to give $\mathbf{A} 2$ was determined to be galactosamine (GalN), using a novel mass tagging LC-MS strategy for detection and quantitation of amino sugars (Ernst, manuscript in preparation). The ion at $m / z 1424.9$ (A3) arises from loss of $\mathrm{C}_{16} \mathrm{H}_{32} \mathrm{O}$ aldehyde, which is eliminated as the result of cleavage between the 2 and 3 position on (18:0)-3-OH. Ions at $\mathrm{m} / \mathrm{z} 1408.9$ (A4) and 1364.9 (A6) are due to losses of palmitic acid (16:0) and (18:0)-3-OH acid, respectively, and are indicative of O-linked fatty acids. The minor ion at $\mathrm{m} / \mathrm{z} 1382.9$ (A5) results from the loss of (18:0)-3-OH ketene from the $\mathrm{N}$-linked (18:0)-3-OH group. Secondary dissociations lead to more abundant ions in the CID spectrum (Figure 2a) such as $m / z^{\circ} 1247.8644$ (loss of (16:0) and GalN; 0.1 ppm), m/z 1203.8381 (loss of (18:0)-3-OH acid and GalN; $0 \mathrm{ppm}$ ), $\mathrm{m} / \mathrm{z} 1124.6614$ (loss of (18:0)-3-OH acid and $\mathrm{C}_{16} \mathrm{H}_{32} \mathrm{O}$ aldehyde; $-0.2 \mathrm{ppm}$ ), and $m / z 947.5985$ (loss of (18:0)-3-OH acid, palmitic acid, and GalN; 0.6 ppm).

Previously, Gibson and coworkers showed that the ion at $m / z^{\circ} 1424.9$ in the MS/MS spectrum of A (Figure 2a), arises from elimination of $\mathrm{C}_{16} \mathrm{H}_{32} \mathrm{O}$ aldehyde, i.e., loss of 240.2 $\mathrm{Da}$ [16]. The authors hypothesized that this ion was formed from the N-linked (18:0)-3-OH acyl group of the reducing glucosamine, resulting from a McLafferty-like rearrangement initiated by the neighboring phosphate group. However, our study supports that the observed loss of $240.2 \mathrm{Da}$ arises from $\mathrm{C}_{16} \mathrm{H}_{32} \mathrm{O}$ elimination from both N-linked and O-linked (18:0)$3-\mathrm{OH}$ fatty acids of the reducing glucosamine. This is supported in the linear ion trap MS $^{3}$ spectrum of $m / z$ 1424.9 (Figure 2b), generated from a loss of $240.2 \mathrm{Da}$ $\left(\mathrm{C}_{16} \mathrm{H}_{32} \mathrm{O}\right)$ from $\mathbf{A}$. The ion at $\mathrm{m} / z 1424.9$ can give rise to either ions $\mathbf{A 7}$ or $\mathbf{A} 8$ (Scheme 2), the latter depicted as the more stable ester and amide forms, respectively, rather than the corresponding enols [40-42]. Either A7 or A8 can fragment by eliminating a second $\mathrm{C}_{16} \mathrm{H}_{32} \mathrm{O}$ $(\mathrm{m} / \mathrm{z} 1184.9, \mathbf{A} 9)$, palmitic acid $(\mathrm{m} / \mathrm{z} 1168.7, \mathbf{A 1 0})$, or GalN ( $\mathrm{m} / \mathrm{z}$ 1263.7; A11). However, only A7 is able to fragment by a loss of acetic acid to form the ion at $\mathrm{m} / \mathrm{z}$ 1364.6 (A12). Subsequent loss of GalN ( $m / z$ 1203.8; A13) followed by palmitic acid leads to the ion at $\mathrm{m} / \mathrm{z} 947.6$ (A14). A14 is diagnostic for confirming $\mathrm{C}_{16} \mathrm{H}_{32} \mathrm{O}$ elimination from the O-linked (18:0)-3-OH fatty acid from $\mathbf{A}$, the parent structure. This is because A8, with a stable acetamide group, undergoes multiple dissociations to form the stable ion at $m / z 707.4$ (A16), with none of the intermediate structures able to produce A14. Thus, with the presence of $m / z 947.6$ (A14) in the $\mathrm{MS}^{3}$ spectra of $\mathrm{m} / \mathrm{z}$ 1424.9 , the data support competitive losses of $\mathrm{C}_{16} \mathrm{H}_{32} \mathrm{O}$ aldehyde from both $\mathrm{N}$ - and O-linked fatty acyls on the reducing glucosamine. Further, this competitive fragmentation suggests that the formation of ions at $\mathrm{m} / \mathrm{z}$ 1424.9 may be better described as initiating from a charge-remote mechanism [43, 44]. In this manner, 
(a)

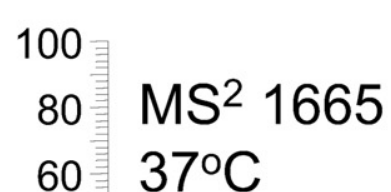

1203.8381

40

20 贯 $\quad 868.4215$

947.5985

$800 \quad 1000$

1124.6614

1247.8644

1408.9344 (A2) (A1)

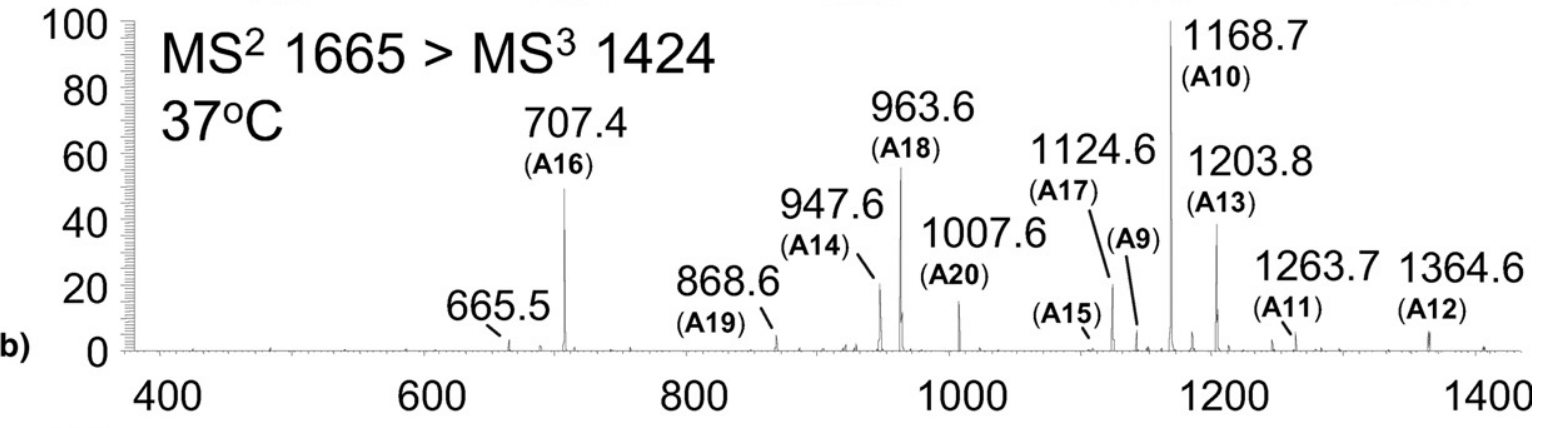

(c)

100

80

$M^{2} 1665>M^{3} 947$

$6037^{\circ} \mathrm{C}$

40

20

20
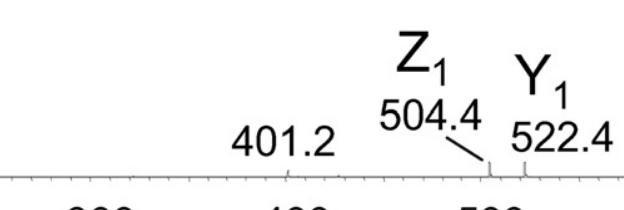

$\begin{array}{llll}300 & 400 \quad 500 & 600\end{array}$

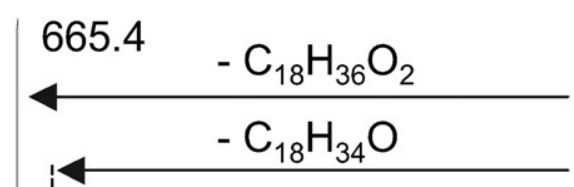

100

100

$\mathrm{MS}^{2}>1665>\mathrm{MS}^{3}>868$

$60 \quad 37^{\circ} \mathrm{C}$

40

(d)

20

258.2

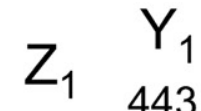

$425.4^{443.2}$

683.4

| 707.4

$700 \quad 800 \quad 900$ 1647.1594

1504.1031

1600 
fragmentation could proceed in a manner analogous to that described for the retro-aldol reaction [45].

Cleavage of the glycosidic bond of the glucosamine disaccharide was necessary for positional assignments of the $\mathrm{N}$ - and O-linked fatty acids, phosphate residues, and additional sugars, which cannot be inferred from the primary dissociations of A. As the CID spectrum of A (Figure 2a) is devoid of glycosidic bond cleavage, further interrogation was necessary. For example, the ion at $m / z^{\circ} 947.6$ (Figure $2 \mathrm{a}$ and Scheme 2 [A14]) results from the dissociation of GalN and both O-linked (18:0)$3-\mathrm{OH}$ and (16:0) fatty acids, leaving the more stable amide linked fatty acids. $\mathrm{MS}^{3}$ of $m / z^{\circ} 947.6$ (Figure 2c) from $A$ results in the formation of ions at $m / z 522.4$ and 504.4, $\mathrm{Y}_{1}$ and $\mathrm{Z}_{1}$ type fragment ions (Scheme 1), respectively, using the nomenclature described by Costello [46-48]. These fragments facilitate assignment of the N-linked substituents to the distal $\left(1^{\prime}-6^{\prime}\right.$ positions) and reducing (1-6 position) ends of the diglucosamine disaccharide as (18:1) and (18:0)-3-OH, respectively. The (18:1) fatty acid derives from the acyloxyacyl group, (18:0)-3-0-(16:0), following the loss of palmitic acid (16:0). Ions at $m / z^{\circ} 683.4$ and 665.4 (Figure $2 b$ ) further confirm the identities of the two N-linked substituents, (18:1) fatty acid at the $2^{\prime}$ position and (18:0)-3-OH acid at the 2 position, respectively. The $Y_{1}$ and $Z_{1}$ ions also assign the phosphate residue to the reducing end of the disaccharide. The $\mathrm{MS}^{3}$ spectrum is devoid of B or C type ions, which would only be observed for species carrying the charge on the distal end of the disaccharide.

Another important aspect in determining lipid A structure comes from identifying that the galactosamine moiety is linked through the phosphate residue on the reducing terminus of the disaccharide core. Following CID of $\mathbf{A}$, there is little evidence for loss of a galactosamine-1-phosphate residue, which would tend to be lost as an ion rather than a neutral, and would fall below the $m / z^{\circ}$ cut-off imposed by the $Q$ value of the linear ion trap. Nonetheless, the $\mathrm{MS}^{3}$ spectrum of $\mathrm{m} / \mathrm{z}$ 868.4 (A19, Scheme 2) from A clearly shows an ion at $\mathrm{m} / \mathrm{z}$ 258.2, which supports the assignment of $\mathbf{A}$ with a galactosamine-1-phosphate residue (Figure 2d).

\section{Determination of the Fatty Acid Structural Heterogeneity in the Dominant Ion Series}

While only a single structure (A) was identified for the base peak at $m / z 1665$ isolated from Fn after growth at $37^{\circ} \mathrm{C}$, multiple structures were found for the same ion from the sample grown at $25^{\circ} \mathrm{C}$ (Figure 1). This was evidenced initially in the $\mathrm{MS}^{2}$ spectrum of $\mathrm{m} / \mathrm{z} 1665$ where an ion at $m / z 919.5663(-0.3 \mathrm{ppm})$ was detected
(Figure 2e). This ion is analogous in structure to the ion at $m / z 947.6$ (A14, Scheme 2) but possessing a shorter fatty acyl chain length (i.e., by $\mathrm{C}_{2} \mathrm{H}_{4}$ ). The other evidence was a small but discernable ion at $\mathrm{m} / \mathrm{z} 1380.8935$ $(-6.0 \mathrm{ppm})$, presumably due to a loss of stearic acid (18:0) from the acyloxyacyl group. While the presence of additional trace isomers was evident in the $\mathrm{MS}^{2}$ spectrum, further experiments were necessary to identify all the possible isomers contained under the $\mathrm{m} / \mathrm{z}$ 1665 peak.

To elucidate all the structures contained under $\mathrm{m} / \mathrm{z}$ 1665 from lipid A isolated after growth at $25^{\circ} \mathrm{C}$, the $\mathrm{MS}^{2}$ fragment at $m / z^{\circ} 1408.9$ (Figure 2e), identified as the loss of palmitic acid from $m / z$ 1665, was chosen for further interrogation and analysis in the linear ion trap. MS ${ }^{3}$ of $m / z 1408.9$ led to the formation of ions at $m / z^{9} 947.6$ and 919.6 (Table 1). These ions represent the combined loss of palmitic acid, GalN, and by deduction reveal the identity of the O-linked fatty acid residing on the 3 position of the reducing glucosamine as (18:0)-3-OH and (20:0)-3-OH, for ions at $m / z^{\circ} 947.6$ and 919.6, respectively (Table 2). As expected, $\mathrm{MS}^{4}$ of $\mathrm{m} / \mathrm{z} 947.6$ resulted in the formation of $\mathrm{Y}_{1}$ and $\mathrm{Z}_{1}$ type fragment ions, $m / z 522$ and 504, respectively, from $\mathbf{A}$. Interestingly, an additional but minor $\mathrm{Y}_{1} / \mathrm{Z}_{1}$ ion series was observed at $\mathrm{m} / \mathrm{z} 494$ and 476, which facilitated assignment of the N-linked substituents to the distal and reducing ends of the glucosamine disaccharide as (20:1) and (16:0)-3-OH, respectively, and lead to the assignment of $\mathbf{B}$ (Table 2). Similarly, $\mathrm{MS}^{4}$ of $m / z^{\circ} 919.6$ from $m / z^{\circ} 1408.9$ also produced two $\mathrm{Y}_{1} / \mathrm{Z}_{1}$ ion pairs, 494/476 and 522/504, and led to the assignment of $\mathbf{C}$ and $\mathbf{D}$. Finally, the $\mathrm{MS}^{2}$ fragment at $m / z 1380.9$, identified as the loss of stearic acid from $m / z 1665$, produced an ion at $m / z$ 919.6 (Table 1 ). $\mathrm{MS}^{4}$ of $m / z^{\circ} 919.6$ produced ions at $m / z$ 494 and 476, and led to the assignment of E. We conclude from the $\mathrm{MS}^{2}>\mathrm{MS}^{4}$ spectra that $\mathrm{m} / \mathrm{z} 1665$ from Fn grown at $25^{\circ} \mathrm{C}$ is an isobaric mixture whose relative abundance suggests that $\mathbf{A} \gg \mathbf{B}+\mathbf{C}+\mathbf{D}+$ E. Note that the absence of $\mathbf{B}-\mathbf{E}$ from the sample grown at $37^{\circ} \mathrm{C}$ cannot be due to a loss of MS dynamic range because of the use of AGC, which effectively normalizes the ion populations between the peaks selected for interrogation by MS/MS.

The ion at $m / z 1637$ was found to be a mixture of isomers whose percent composition changed dramatically between the two growth temperatures. The base peak in the ESI-MS spectrum of lipid A from Fn grown at $25^{\circ} \mathrm{C}$ is $m / z^{\circ} 1637.1425$ (0.3 ppm; Figure 1a) and its MS/MS spectrum measured in the FT-ICR is shown in Figure 3a. Two distinct ions from the

Figure 2. (a) High-resolution MS/MS spectrum of $m / z 1665$ from Fn lipid A grown at $37^{\circ} \mathrm{C}$; (b) Ion trap (IT) MS ${ }^{3}$ spectrum of $\mathrm{m} / \mathrm{z} 1424.9$ derived from $\mathrm{m} / \mathrm{z} 1665\left(37^{\circ} \mathrm{C}\right)$; (c) IT MS ${ }^{3}$ spectrum of $\mathrm{m} / \mathrm{z} 947.6$ derived from $\mathrm{m} / \mathrm{z} 1665\left(37^{\circ} \mathrm{C}\right)$; (d) IT MS ${ }^{3}$ spectrum of $\mathrm{m} / \mathrm{z} 868.4$ derived from $\mathrm{m} / \mathrm{z} 1665\left(37^{\circ} \mathrm{C}\right)$; (e) High-resolution MS/MS spectrum of $m / z 1665$ from Fn lipid A grown at $25^{\circ} \mathrm{C}$. 


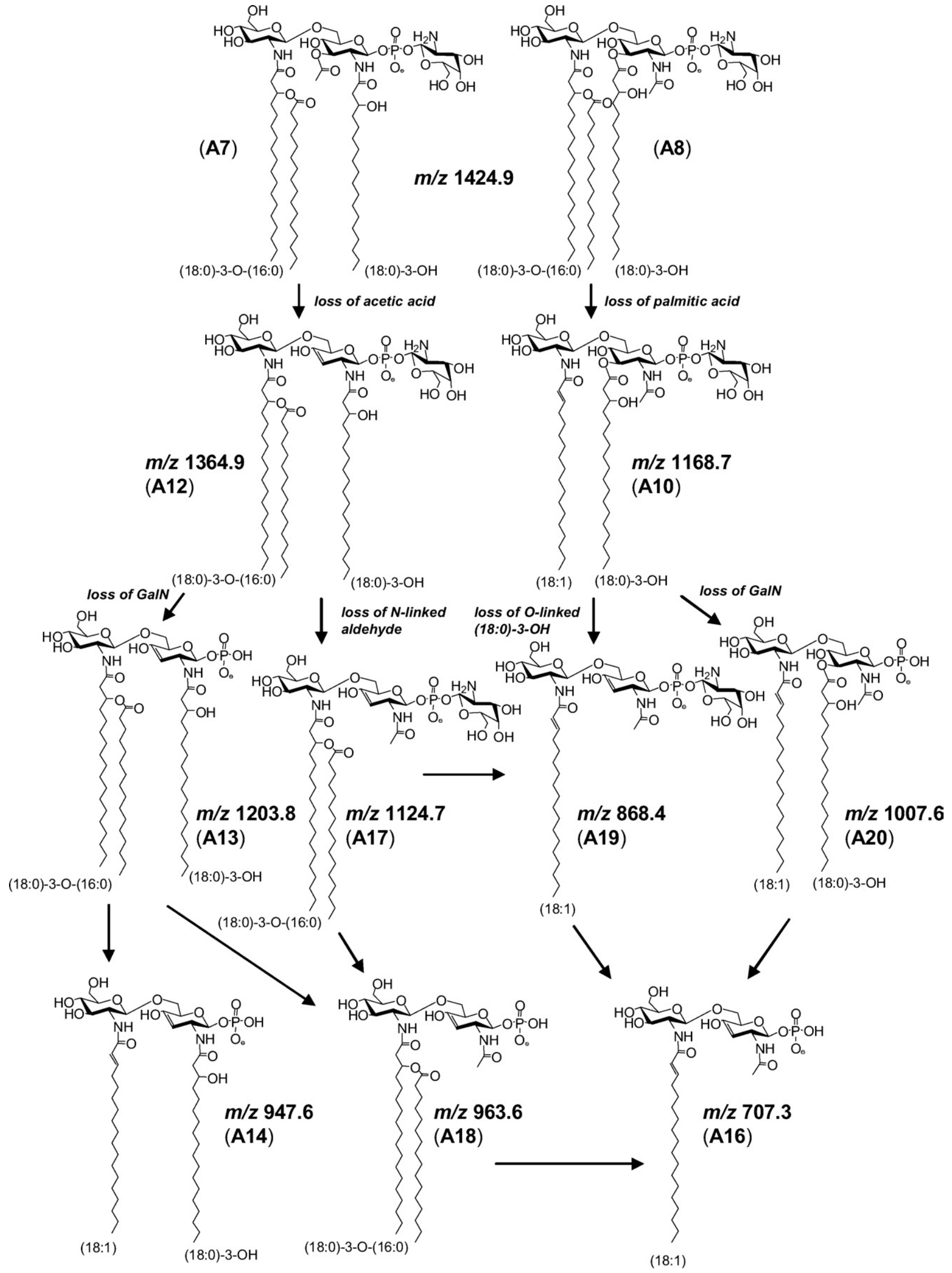

Scheme 2. MS $^{3}$ fragmentation of $m / z 1424.9$ derived from A $(m / z$ 1665). 
Table 1. Fragment ion intensities from selected linear ion trap $\mathrm{MS}^{\mathrm{n}}$ spectra

\begin{tabular}{|c|c|c|c|c|c|c|c|c|c|}
\hline Temp. & $\mathrm{MS}^{2}$ Parent & $\mathrm{MS}^{2}$ Product & R.I. & $\mathrm{MS}^{3}$ Product & R.I. & $Y_{1}-/ Z_{1}$-lons & R.I. & $\sigma$ & Struct. $^{a}$ \\
\hline \multirow[t]{5}{*}{$25^{\circ} \mathrm{C}$} & 1665.1 & $1408.9-(16: 0)$ & 100 & 947.6 & 100 & $522 / 504$ & 100 & $1.0 \mathrm{e}^{6}$ & $A$ \\
\hline & & & & & & $494 / 476$ & 2 & $2.0 e^{4}$ & B \\
\hline & & & & 919.6 & 8 & $494 / 476$ & 100 & $8.0 e^{4}$ & $\mathrm{C}$ \\
\hline & & & & & & $522 / 504$ & 10 & $8.0 e^{3}$ & $\mathrm{D}$ \\
\hline & & 1380.9-(18:0) & 2 & 919.6 & 100 & $494 / 476$ & 100 & $2.0 \mathrm{e}^{4}$ & $\mathrm{E}$ \\
\hline $37^{\circ} \mathrm{C}$ & 1665.1 & $1408.9-(16: 0)$ & 100 & 947.6 & 100 & $522 / 504$ & 100 & $1.0 \mathrm{e}^{6}$ & A \\
\hline \multirow[t]{3}{*}{$25^{\circ} \mathrm{C}$} & 1637.1 & $1380.9-(16: 0)$ & 100 & 919.6 & 100 & $494 / 476$ & 100 & $1.0 \mathrm{e}^{6}$ & $\mathrm{~F}$ \\
\hline & & & & & & $522 / 504$ & 4 & $4.0 \mathrm{e}^{4}$ & G \\
\hline & & & & 947.6 & 11 & $522 / 504$ & 100 & $1.1 \mathrm{e}^{5}$ & $\mathrm{H}$ \\
\hline \multirow[t]{4}{*}{$37^{\circ} \mathrm{C}$} & 1637.1 & $1380.9-(16: 0)$ & 100 & 947.6 & 100 & $522 / 504$ & 100 & $1.0 e^{6}$ & $\mathrm{H}$ \\
\hline & & & & 919.6 & 80 & $494 / 476$ & 100 & $8.0 e^{5}$ & $\mathrm{~F}$ \\
\hline & & & & & & $522 / 504$ & 2 & $1.6 \mathrm{e}^{4}$ & $\mathrm{G}$ \\
\hline & & $1408.9-(14: 0) 7$ & & 947.6 & 100 & $522 / 504$ & 100 & $7.0 e^{4}$ & 1 \\
\hline \multirow[t]{6}{*}{$25^{\circ} \mathrm{C}$} & 1609.1 & $1352.9-(16: 0)$ & 100 & 919.6 & 100 & $494 / 476$ & 100 & $1.0 \mathrm{e}^{6}$ & $\mathrm{~J}$ \\
\hline & & & & & & $522 / 504$ & 5 & $5.0 e^{4}$ & $\mathrm{~K}$ \\
\hline & & & & 891.5 & 70 & $494 / 476$ & 100 & $7.0 e^{5}$ & L \\
\hline & & & & & & $466 / 448$ & 3 & $2.1 \mathrm{e}^{4}$ & $\mathrm{M}$ \\
\hline & & $1380.9-(14: 0)$ & 6 & 919.6 & 100 & $494 / 476$ & 100 & $6.0 \mathrm{e}^{4}$ & $\mathrm{~N}$ \\
\hline & & & & 947.6 & 12 & $522 / 504$ & 100 & $7.2 e^{3}$ & 0 \\
\hline \multirow[t]{8}{*}{$37^{\circ} \mathrm{C}$} & 1609.1 & $1380.9-(14: 0)$ & 100 & 947.6 & 100 & $522 / 504$ & 100 & $1.0 \mathrm{e}^{6}$ & 0 \\
\hline & & & & 919.6 & 60 & $494 / 476$ & 100 & $6.0 e^{5}$ & $\mathrm{~N}$ \\
\hline & & $1352.9-(16: 0)$ & 80 & 919.6 & 100 & $494 / 476$ & 100 & $8.0 e^{5}$ & $\mathrm{~J}$ \\
\hline & & & & & & $522 / 504$ & 11 & $8.8 e^{4}$ & $\mathrm{~K}$ \\
\hline & & & & 891.5 & 20 & $494 / 476$ & 100 & $1.6 \mathrm{e}^{5}$ & L \\
\hline & & & & & & $466 / 448$ & 60 & $9.6 \mathrm{e}^{4}$ & $\mathrm{M}$ \\
\hline & & & & 947.6 & 12 & $522 / 504$ & 100 & $9.6 \mathrm{e}^{4}$ & $\mathrm{P}$ \\
\hline & & $1408.9-(12: 0)$ & 16 & 947.6 & 100 & $522 / 504$ & 100 & $1.6 \mathrm{e}^{5}$ & $\mathrm{Q}$ \\
\hline \multirow[t]{6}{*}{$25^{\circ} \mathrm{C}$} & 1581.0 & $1324.8-(16: 0)$ & 100 & 891.5 & 100 & $494 / 476$ & 100 & $1.0 \mathrm{e}^{6}$ & $\mathrm{R}$ \\
\hline & & & & 863.5 & 2 & $466 / 448$ & 100 & $2.0 \mathrm{e}^{4}$ & $\mathrm{~S}$ \\
\hline & & & & 919.6 & 1 & $494 / 476$ & 100 & $1.0 \mathrm{e}^{4}$ & $\mathrm{~T}$ \\
\hline & & $1352.9-(14: 0)$ & 24 & 919.6 & 100 & $494 / 476$ & 100 & $2.4 e^{5}$ & U \\
\hline & & & & & & $522 / 504$ & 5 & $1.2 e^{4}$ & V \\
\hline & & & & 891.5 & 50 & $494 / 476$ & 100 & $1.2 e^{5}$ & W \\
\hline \multirow[t]{7}{*}{$25^{\circ} \mathrm{C}$} & 1693.2 & $1436.9-(16: 0)$ & 100 & 947.6 & 100 & $522 / 504$ & 100 & $1.0 e^{6}$ & $x$ \\
\hline & & & & 975.6 & 50 & $522 / 504$ & 100 & $5.0 e^{5}$ & $Y$ \\
\hline & & & & & & $550 / 532$ & 100 & $5.0 \mathrm{e}^{5}$ & Z \\
\hline & & & & 919.6 & 6 & $494 / 476$ & 100 & $6.0 e^{4}$ & AA \\
\hline & & 1408.9-(18:0) & 13 & 947.6 & 100 & $522 / 504$ & 100 & $1.3 e^{5}$ & $\mathrm{BB}$ \\
\hline & & & & & & $494 / 476$ & 3 & $3.9 e^{3}$ & $\mathrm{CC}$ \\
\hline & & & & 919.6 & 6 & $494 / 476$ & 100 & $7.8 e^{3}$ & DD \\
\hline \multirow[t]{4}{*}{$37^{\circ} \mathrm{C}$} & 1693.2 & $1436.9-(16: 0)$ & 100 & 975.6 & 100 & $550 / 532$ & 100 & $1.0 \mathrm{e}^{6}$ & Z \\
\hline & & & & & & $522 / 504$ & 60 & $6.0 e^{5}$ & $\bar{Y}$ \\
\hline & & & & 947.6 & 68 & $522 / 504$ & 100 & $6.8 e^{5}$ & $x$ \\
\hline & & $1408.9-(18: 0)$ & 16 & 947.6 & 100 & $504 / 522$ & 100 & $1.6 \mathrm{e}^{5}$ & BB \\
\hline
\end{tabular}

aSee Table 2. Relative intensities (R.I.) correspond to the dissociation pathways indicated (not the whole spectrum).

dissociation of the O-linked hydroxy fatty acid at the 3 position of the glucosamine disaccharide were observed (Figure 3a) at $m / z^{\circ} 1336.8764(0.6 \mathrm{ppm})$ and $\mathrm{m} / \mathrm{z} 1364.9061(-0.6 \mathrm{ppm})$ for the loss of $(18: 0)-3-\mathrm{OH}$ and (16:0)-3-OH, respectively. Losses of $\mathrm{C}_{16} \mathrm{H}_{32} \mathrm{O}$ or $\mathrm{C}_{14} \mathrm{H}_{28} \mathrm{O}$ aldehyde from either the $\mathrm{N}$ - or O-linked fatty acyls of the reducing glucosamine were also observed at $\mathrm{m} / \mathrm{z} 1396.8971(0.3 \mathrm{ppm})$ and 1424.9289 $(0.6 \mathrm{ppm})$, respectively. More evidence for the presence of a mixture was found in the ions at $\mathrm{m} / \mathrm{z}$ $1175.8061(-0.6 \mathrm{ppm})$ resulting from the combined loss of GalN and (18:0)-3-OH and $m / z 1203.8385$ (0.3 ppm) resulting from the loss of GalN and (16:0)-3$\mathrm{OH}$. Further dissociation of these ions by removal of the fatty acid esterified on the acyloxyacyl group of the 2-postion of the distal glucosamine leads lead to stable ions at $\mathrm{m} / \mathrm{z} 919.5669(0.3 \mathrm{ppm})$ and $947.5987(0.8$ $\mathrm{ppm})$, ions that must derive from independent structures present in the parent ion.

While not observed in the high-resolution MS/MS spectrum from the $25^{\circ} \mathrm{C}$ sample, MS/MS of $m / z 1637$ from the $37^{\circ} \mathrm{C}$ sample produced an ion at $\mathrm{m} / \mathrm{z}$ $1408.9340(0.6 \mathrm{ppm})$ resulting from the loss of myristic acid (Figure $3 b$ ). This supports a structure in which myristate, rather than palmitate, is esterified to the amide linked fatty acyl on the distal glucosamine. By comparison with the ion for loss of palmitic acid $(\mathrm{m} / \mathrm{z} 1380.9)$, the $m / z 1408.9 / 1380.9$ ratio was found to be $\sim 0.08$. Presumably, the abundance of this structure is small and comprises only a small fraction of 
Table 2. Lipid A structural isomers and fatty acyl positions for $\mathrm{m} / \mathrm{z}$ 1581-1693

\begin{tabular}{|c|c|c|c|c|}
\hline$(\mathrm{M}-\mathrm{H})^{-}$ & Structure & $2^{\prime}$ position & 2 position & 3 position \\
\hline \multirow[t]{5}{*}{1665.1733} & $A$ & $(18: 0)-3-0-(16: 0)$ & $(18: 0)-3-\mathrm{OH}$ & $(18: 0)-3-\mathrm{OH}$ \\
\hline & B & $(20: 0)-3-0-(16: 0)$ & $(16: 0)-3-\mathrm{OH}$ & $(18: 0)-3-\mathrm{OH}$ \\
\hline & $\mathrm{C}$ & $(18: 0)-3-0-(16: 0)$ & $(16: 0)-3-\mathrm{OH}$ & $(20: 0)-3-\mathrm{OH}$ \\
\hline & D & $(16: 0)-3-0-(16: 0)$ & $(18: 0)-3-\mathrm{OH}$ & $(20: 0)-3-\mathrm{OH}$ \\
\hline & $\mathrm{E}$ & $(18: 0)-3-0-(18: 0)$ & $(16: 0)-3-\mathrm{OH}$ & $(18: 0)-3-\mathrm{OH}$ \\
\hline \multirow[t]{4}{*}{1637.4250} & $\mathrm{~F}$ & $(18: 0)-3-0-(16: 0)$ & $(16: 0)-3-\mathrm{OH}$ & $(18: 0)-3-\mathrm{OH}$ \\
\hline & $\mathrm{G}$ & $(16: 0)-3-0-(16: 0)$ & $(18: 0)-3-\mathrm{OH}$ & $(18: 0)-3-\mathrm{OH}$ \\
\hline & $\mathrm{H}$ & $(18: 0)-3-0-(16: 0)$ & $(18: 0)-3-\mathrm{OH}$ & $(16: 0)-3-\mathrm{OH}$ \\
\hline & 1 & $(18: 0)-3-0-(14: 0)$ & $(18: 0)-3-\mathrm{OH}$ & $(18: 0)-3-\mathrm{OH}$ \\
\hline \multirow[t]{8}{*}{1609.1107} & $J$ & $(18: 0)-3-0-(16: 0)$ & $(16: 0)-3-\mathrm{OH}$ & $(16: 0)-3-\mathrm{OH}$ \\
\hline & K & $(16: 0)-3-0-(16: 0)$ & $(18: 0)-3-\mathrm{OH}$ & $(16: 0)-3-\mathrm{OH}$ \\
\hline & L & $(16: 0)-3-0-(16: 0)$ & $(16: 0)-3-\mathrm{OH}$ & (18:0)-3-OH \\
\hline & M & $(18: 0)-3-0-(16: 0)$ & $(14: 0)-3-\mathrm{OH}$ & (18:0)-3-OH \\
\hline & $\mathrm{N}$ & $(18: 0)-3-0-(14: 0)$ & $(16: 0)-3-\mathrm{OH}$ & $(18: 0)-3-\mathrm{OH}$ \\
\hline & 0 & $(18: 0)-3-0-(14: 0)$ & $(18: 0)-3-\mathrm{OH}$ & $(16: 0)-3-\mathrm{OH}$ \\
\hline & $P$ & $(18: 0)-3-0-(16: 0)$ & $(18: 0)-3-\mathrm{OH}$ & $(14: 0)-3-\mathrm{OH}$ \\
\hline & Q & $(18: 0)-3-0-(12: 0)$ & $(18: 0)-3-\mathrm{OH}$ & $(18: 0)-3-\mathrm{OH}$ \\
\hline \multirow[t]{6}{*}{1581.0794} & $\mathrm{R}$ & $(16: 0)-3-0-(16: 0)$ & $(16: 0)-3-\mathrm{OH}$ & $(16: 0)-3-\mathrm{OH}$ \\
\hline & $\mathrm{S}$ & $(16: 0)-3-0-(16: 0)$ & $(14: 0)-3-\mathrm{OH}$ & $(18: 0)-3-\mathrm{OH}$ \\
\hline & $\mathrm{T}$ & $(18: 0)-3-0-(16: 0)$ & $(16: 0)-3-\mathrm{OH}$ & $(14: 0)-3-\mathrm{OH}$ \\
\hline & $U$ & $(18: 0)-3-0-(14: 0)$ & $(16: 0)-3-\mathrm{OH}$ & $(16: 0)-3-\mathrm{OH}$ \\
\hline & V & $(16: 0)-3-0-(14: 0)$ & $(18: 0)-3-\mathrm{OH}$ & $(16: 0)-3-\mathrm{OH}$ \\
\hline & W & $(16: 0)-3-0-(14: 0)$ & $(16: 0)-3-\mathrm{OH}$ & $(18: 0)-3-\mathrm{OH}$ \\
\hline \multirow{7}{*}{1693.2046} & $x$ & $(18: 0)-3-0-(16: 0)$ & $(18: 0)-3-\mathrm{OH}$ & $(20: 0)-3-\mathrm{OH}$ \\
\hline & Y & $(20: 0)-3-0-(16: 0)$ & $(18: 0)-3-\mathrm{OH}$ & $(18: 0)-3-\mathrm{OH}$ \\
\hline & Z & $(18: 0)-3-0-(16: 0)$ & $(20: 0)-3-\mathrm{OH}$ & $(18: 0)-3-\mathrm{OH}$ \\
\hline & AA & $(18: 0)-3-0-(16: 0)$ & $(16: 0)-3-\mathrm{OH}$ & $(22: 0)-3-\mathrm{OH}$ \\
\hline & BB & $(18: 0)-3-0-(18: 0)$ & $(18: 0)-3-\mathrm{OH}$ & (18:0)-3-OH \\
\hline & $\mathrm{CC}$ & $(20: 0)-3-0-(18: 0)$ & $(16: 0)-3-\mathrm{OH}$ & $(18: 0)-3-\mathrm{OH}$ \\
\hline & DD & $(18: 0)-3-0-(18: 0)$ & $(16: 0)-3-\mathrm{OH}$ & $(20: 0)-3-O H$ \\
\hline
\end{tabular}

the total ion abundance for $m / z$ 1637. This estimate is further supported in secondary dissociations, where the combined loss of myristic acid (14:0) + GalN yield a small but discernable ion at $\mathrm{m} / \mathrm{z} 1247.8645(0.2$ ppm). Comparison of its relative abundance with $\mathrm{m} / \mathrm{z}$ 1219.8337 (0.6 ppm; loss of palmitic acid + GalN) produced a similar ratio of 0.04 .

Utilizing the $\mathrm{MS}^{n}$ strategy described above for $\mathrm{m} / \mathrm{z}$ $1665, \mathrm{~m} / \mathrm{z} 1637$ was found to be a heterogeneous mixture of structures $\mathbf{F}, \mathbf{G}$, and $\mathbf{H}$ from Fn grown at $25^{\circ} \mathrm{C}$, and $\mathbf{F}, \mathbf{G}, \mathbf{H}$, and $\mathbf{I}$ from $\mathrm{Fn}$ grown at $37^{\circ} \mathrm{C}$ (Table 2). The components of the mixture changed dramatically between the two growth temperatures. To illustrate, F, G, and I can dissociate by loss of (18:0)-3-OH to form $m / z$ 1336.9, while $\mathbf{H}$ can dissociate by loss of (16:0)-3-OH to produce $m / z$ 1364.9. The measured $m / z$ 1336.9/1364.9 ratio was $\sim 6.6$ and changed to $\sim 0.65$ for growth at 25 versus $37^{\circ} \mathrm{C}$, respectively. Further dissociation leads to ions at $\mathrm{m} / \mathrm{z}$ 1175.8 [loss of (18:0)-3-OH and GalN] and 1203.8 [loss of (16:0)-3-OH and GalN]. Similarly, the 1175.8/ 1203.8 ratio was $\sim 6.2$ and changed to $\sim 0.56$ for growth at $25^{\circ} \mathrm{C}$ versus $37^{\circ} \mathrm{C}$, respectively. Additionally, note that $\mathbf{F}$ and $\mathbf{G}$ are able to produce, upon successive dissociations, the ion at $m / z$ 919.6, while $\mathbf{H}$ and I can produce the analogous ion at $m / z$ 947.6. The $m / z 919.6 / 947.6$ ratio was found to be $\sim 5.6$ for the $25^{\circ} \mathrm{C}$ sample and $\sim 0.38$ for the $37^{\circ} \mathrm{C}$ sample. Since the abundance of I was found to be small, based on the minor loss of myristic acid, one can presume that most of the ion current from $\mathrm{m} / \mathrm{z} 947$ arises from structure $\mathbf{H}$. Furthermore, Table 1 suggests that $\mathbf{G}$ is also a minor species in the mixture based on the $\mathrm{MS}^{4}$ spectra of $\mathrm{m} / \mathrm{z} 919.6$ isolated from $\mathrm{m} / \mathrm{z} 1380.9$ (loss of palmitic acid). Thus, most of the ion current from $\mathrm{m} / \mathrm{z}$ 919.6 must arise from F. Taken collectively, the ion ratios suggest that $\mathbf{F}$ is the dominant structure at $25{ }^{\circ} \mathrm{C}$, while $\mathbf{H}$ is dominant at $37^{\circ} \mathrm{C}$.

The peak at $m / z 1609$ was found to have the greatest fatty acid heterogeneity. This peak comprised $\sim 37 \%$ relative intensity $(\mathrm{m} / \mathrm{z} 1637$ base) in the mass spectrum from lipid A isolated after growth at $25^{\circ} \mathrm{C}$, but was $<2 \%$ relative intensity $(\mathrm{m} / \mathrm{z} 1665$ base $)$ in the mass spectrum from lipid $\mathrm{A}$ isolated after growth at $37^{\circ} \mathrm{C}$ (Figure 1). The eight structures J-Q for $m / z^{\circ} 1609$ are found in Table 2. The structures differed by the identities of the $\mathrm{O}$ - and $\mathrm{N}$-linked substituents of the reducing glucosamine that were identified as either (18:0)-3-OH, (16:0)-3-OH, or (14: $0)-3-\mathrm{OH}$ hydroxylated fatty acids. Structures can be grouped by the nature of the amide linked acyloxyacyl group of the distal glucosamine, identified as (18:0)-3-0-(16:0) (J, M, P), (16:0)-3-0-(16:0) (K, L), (18:0)-3-0-(14:0) (N, O), or (18:0)-3-0-(12:0) (Q). As 
(a)

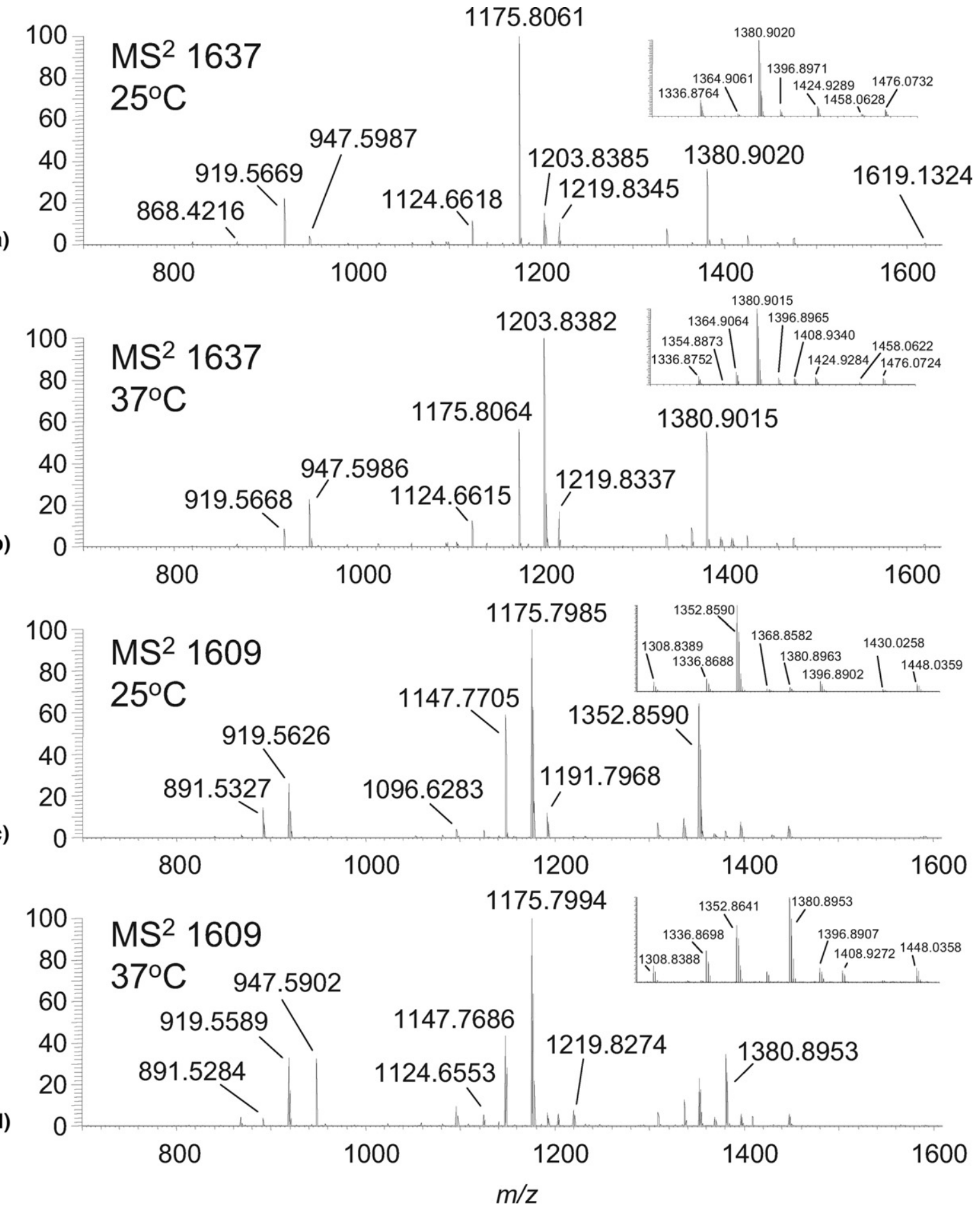

Figure 3. (a) High-resolution MS/MS spectrum of $m / z 1637$ from Fn lipid A grown at $25^{\circ} \mathrm{C}$; (b) at $37^{\circ} \mathrm{C}$; (c) High-resolution MS/MS spectrum of $m / z 1609$ from Fn lipid A grown at $25^{\circ} \mathrm{C}$; (d) at $37^{\circ} \mathrm{C}$.

with the other peaks investigated, the contributions of each structure that comprise $\mathrm{m} / \mathrm{z} 1609$ changed dramatically between the two growth temperatures studied. This was evidenced by examining the relative ion intensities for representing primary, secondary, and multiple dissociations from $\mathrm{m} / \mathrm{z} 1609$ in the MS/MS spectra for the two growth conditions (Figure $3 \mathrm{c}$ and $\mathrm{d}$ ). As an example, the stable amide-linked fatty acid fragment ions at $m / z$ 947.6, 919.6, and 891.5 were found in a ratio of $\sim 0.96: 1.0: 0.12$ for the $37^{\circ} \mathrm{C}$ sample and $\sim 0.01: 1.0: 0.54$ ratio for the $25^{\circ} \mathrm{C}$ sample. The dramatic changes in ion ratios, combined with the significant changes in relative ion abundance for the deprotonated molecules, indicate a massive lipid A remodeling effect from a change in growth temperature. 


\section{Modeling the Environmental Regulation of Lipid A}

The use of precursor and fragment ion relative abundance ratios to quantitatively determine components of a mixture is problematic for several reasons. However, we chose this route in spite of two pitfalls. First, electrospray ionization efficiencies vary between structures, making their absolute abundances difficult to determine [49]. Second, collisional fragmentation efficiencies between similar structures can vary, even in the present case when comparing similar bond cleavages possessing different leaving groups. Both of these issues can be addressed with authentic analytical standards via a calibration response. However, commercial sources of lipid A are limited in availability and tend to be derived from natural sources where the molecular structure(s) are often unique to the corresponding species. Here we present a method for circumventing these problems.

Using an infusion tandem mass spectrometry approach, we used both precursor and fragment ion abundances to detect qualitative changes in Fn lipid A structures between different growth conditions. This was done by first utilizing eq 1 .

$$
\sigma=\mathrm{RI} \mathrm{MS}^{2} * \mathrm{RI} \mathrm{MS}^{3} * \mathrm{RI} \mathrm{MS}^{4}
$$

where $\sigma$ is a weighting coefficient for an individual structure (A-DD), RI MS ${ }^{2}$ is the relative intensity of the $\mathrm{MS}^{2}$ product ions following the loss of fatty acid from the acyloxyacyl group from the parent ions, RI MS $^{3}$ is the relative intensity of the $\mathrm{MS}^{3}$ product ions following the combined loss of GalN and the hydroxy-fatty acid located at the 3 position, and RI MS ${ }^{4}$ is the relative intensity of the $\mathrm{MS}^{4} \mathrm{Y}$ - and Z-type product ions following cleavage of the glycosidic bond of the diglucosamine core. The relative intensity values, RI MS ${ }^{2}$, RI $\mathrm{MS}^{3}$, and RI MS ${ }^{4}$ are found in Table 1. The tandem MS weighting coefficient $\sigma$ was further manipulated to yield $\omega$, using eq 2 ,

$$
\omega=\% \mathrm{MS}^{1} *\left[\sigma / \sum \sigma_{\mathrm{MI}}\right]
$$

where $\% \mathrm{MS}^{1}$ is the percent contribution for the deprotonated molecule ion in the MS spectra and $\Sigma \sigma_{\mathrm{MI}}$ is the sum of $\sigma$ for all structures comprising a deprotonated molecule under a given set of sample conditions. Thus, $\omega$ represents a composite weighting factor for an individual structure (A-DD), derived from both the MS data (Figure 1) and the tandem $\mathrm{MS}^{n^{\circ}}$ data (Table 1).

The value of $\omega$ can be used to estimate the relative abundance of a particular structure derived from a common precursor ion, and this in turn can be used to propose a rank order of abundance for lipid A structures A-DD under the two Fn growth conditions. Changes detected between the two growth conditions are indicative of remodeling and reflect changes in the expression of genes responsible for lipid A biosynthesis. This is also the case for monosaccharide addition, which (a)

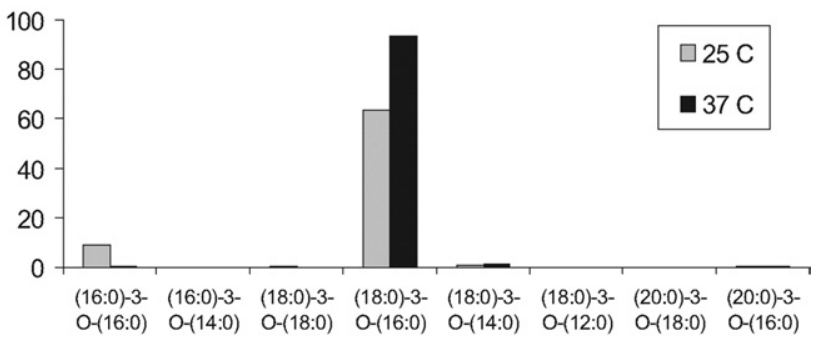

(b)

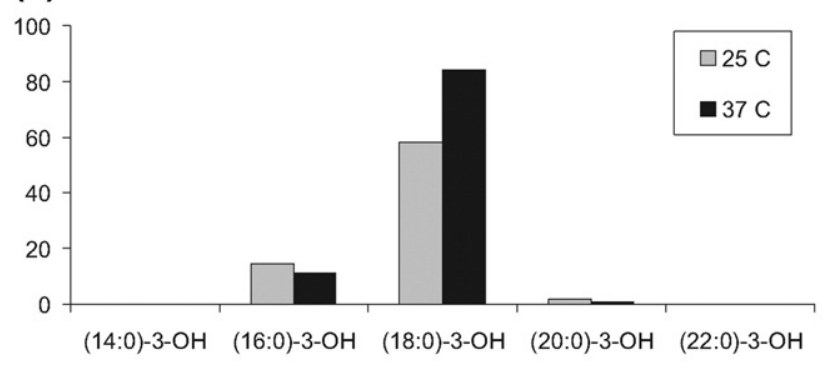

(c)

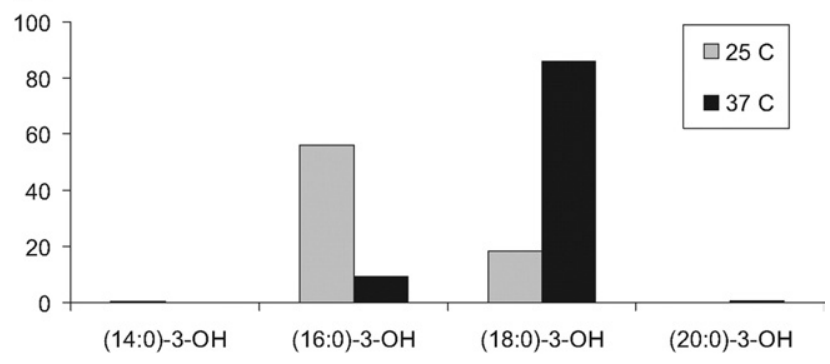

Figure 4. Temperature-dependent lipid A remodeling as a function of acyl group frequency $(\tau)$ for: (a) the acyloxyacyl group $\left(2^{\prime}\right.$ position); (b) the 3 position; (c) the 2 position. Values derive from $\mathrm{m} / \mathrm{z} 1581-1693$ but $\omega$ was calculated using $\% \mathrm{MS}^{1}$ values inclusive of the hexose modified ion series (i.e., $m / z$ 1771-1827).

by examination of the MS spectra in Figure 1, the hexose containing lipid A ions at $\mathrm{m} / \mathrm{z} 1771,1799$, and 1827 comprised $\sim 26 \%$ of the lipid A ion current from the $25^{\circ} \mathrm{C}$ sample, but was $<5 \%$ for the $37^{\circ} \mathrm{C}$ sample.

Using Table 1 and Figure 1 to derive $\omega$, the composite weighting factors were used to visualize the remodeling of all structures (A-DD) for each acyl position for the two growth temperatures studied using eq 3

$$
\tau=\sum \omega
$$

where $\tau$ represents the sum of all $\omega$ for all structures bearing a defined acyl group at a defined position on the diglucosamine core. Figure 4 displays $\tau$, the frequency of acyl groups, for the 2,3 , and $3^{\prime}$ positions. The data indicate that (18:0)-3-O-(16:0) is the dominant substituent at the $3^{\prime}$ position and is enriched following growth at $37^{\circ} \mathrm{C}$ (Figure 4a). By contrast, the (16:0)-3-O(16:0) substituent is greatly reduced following growth at $37^{\circ} \mathrm{C}$. Further analysis of the esterified fatty acid component of the acyloxyacyl group showed that 
palmitic acid was the dominant substitution and was elevated at $37^{\circ} \mathrm{C}$ relative to $25^{\circ} \mathrm{C}$ (data not shown). For the 3 position, the most common substituent was (18: $0)-3-\mathrm{OH}$; and was enriched at $37^{\circ} \mathrm{C}$ relative to $25^{\circ} \mathrm{C}$ (Figure $4 \mathrm{~b}$ ). For the 2 position, however, the most significant change was observed (Figure 4c). Growth of Fn at $25^{\circ} \mathrm{C}$ indicates that (16:0)-3-OH is the dominant substituent but for growth at $37^{\circ} \mathrm{C}$ the trend is reversed and favors (18:0)-3-OH. These observations implicate the 2 position of Fn lipid A as the major location for temperature-dependent remodeling of fatty acyl groups.

The data suggest that acyl chain remodeling favors (18:0)-3-OH at the higher temperature and is most pronounced at the 2 position but also occurs for the 3 and 2 ' positions. This can help to explain the dramatic shift in ion intensities contained between the two samples in the ESI-MS spectra (Figure 1). For example, the ion at $m / z 1581\left(25^{\circ} \mathrm{C}\right)$ is almost entirely comprised of $\mathbf{R}$, $\mathrm{U}$, and $\mathrm{W}$ (Table 1), all of which possess a (16:0)-3-OH at the 2 position (Table 2). It follows that if this position is preferentially remodeled to (18:0)-3-OH, then this ion would not be predicted to be observed in the MS spectrum from the lipid A sample isolated from Fn growth at $37^{\circ} \mathrm{C}$. Similarly, the ion at $\mathrm{m} / \mathrm{z} 1609\left(25^{\circ} \mathrm{C}\right)$ is dominated by J and L; both of these possess a (16:0)$3-\mathrm{OH}$ at the 2 position and both are greatly reduced in the MS spectrum from the $37^{\circ} \mathrm{C}$ sample. The base peak in the MS spectrum at $25^{\circ} \mathrm{C}, \mathrm{m} / \mathrm{z} 1637$, consists primarily of F. Substitution of (16:0)-3-OH for (18:0)-3-OH at the 2 position in F would produce $A(m / z 1665)$, the base peak $(m / z 1665)$ in the MS spectrum at $37^{\circ} \mathrm{C}$. Note that A, having both the 2 and 3 positions occupied with (18:0)-3-OH would not be predicted to shift to higher $\mathrm{m} / \mathrm{z}$ at the higher temperature; the weak increase of $\mathrm{m} / \mathrm{z}$ $1693\left(37^{\circ} \mathrm{C}\right)$ supports this conclusion.

It follows that the measured changes in $\sigma$ and $\omega$ between the sample sets reflect relative changes in sample composition. By comparison of similar dissociation pathways between all possible isomers, discrimination effects by ion activation and dissociation are minimized as much as possible as fragment ions are similar with respect to structure, degrees of freedom, and charge localization. Moreover, fragment ions are collisionally cooled before their isolation for subsequent activation and dissociation, so that energetic biases caused by CID would be minimized rather than be perpetuated through multiple stages of $\mathrm{MS}^{n}$. An advantage of the LTQ is the use of AGC, which sets the number of ions for both the linear ion trap and ICR cell [32].ŠIfšthešmaximumšfillštimešisšsetšhighšrelativeštošthe actual fill time needed, then equivalent numbers of ions are analyzed between samples. This has the effect of decoupling the incident ESI ion current on subsequent $\mathrm{MS}^{n}$ events and allows measurement of fragment ion relative intensities (e.g., $\sigma$ ) that are less susceptible to diurnal variations in ESI ion current, ion source tuning parameters, and transmission dynamics through the pressure gradient to the LTQ analyzer. Moreover, given the normalization effect of AGC, the ability to detect the low abundance isomers contained within a peak is a direct measure of the methods dynamic range. For example, $m / z 1693\left(25^{\circ} \mathrm{C}\right)$ gave a ratio of $\sigma$ values of 250 (i.e., $\mathrm{X} / \mathrm{CC}$ ), thus providing an estimate of the dynamic range under the current set of ion population settings.

Measurements in both the LTQ and ICR cell were beneficial to the data interpretation. Comparison of ion ratios were similar between the two detectors at high signal intensity but tended to be dissimilar at low intensities. This discrepancy was due to the data reduction feature of the instrument control program, which subtracts out $\sim 2.9$ times the standard deviation of the noise from the FT transient following its conversion to a mass spectrum. Thus, from this standpoint, the use of ion ratios was favored from the LTQ data. The mass accuracy of the FT-ICR MS data were in agreement, but did little to authenticate the elemental compositions of the deprotonated molecules, given their high molecular weights. Further, most of the ions were mixtures of isobaric structures and deconvolution of the isomers had to come from $\mathrm{MS}^{n}$ analysis. For MS/MS, the FT-ICR data were of great value as fragment ions and inferred neutral losses were realized with great accuracy ( $<5$ ppm in most cases). Moreover, low intensity fragment ions that could be mistaken as noise in the LTQ could rapidly be identified in the FT-ICR by virtue of their mass defect and isotopic distribution.

\section{Conclusions}

The results show that a unique profile of Fn U112 lipid A molecular structures are produced in response to growth at $25^{\circ} \mathrm{C}$ versus $37^{\circ} \mathrm{C}$. Deprotonated molecules were found to be heterogeneous mixtures, sharing a conserved glucosamine disaccharide backbone, a galactosamine-1-phosphate linked to the reducing glucosamine, but differed as to the identities of the $\mathrm{N}$ - and O-linked fatty acyl substituents. The extensive heterogeneity of structures observed has not been reported previously. Estimates for the relative abundance of each isomer were derived from MS relative abundance ratios and fragment ion ratios from comparable dissociation pathways. The results suggest a remodeling pathway in which the amide linked fatty acid of the reducing glucosamine favors a 3-hydroxyhexadecanoic acid substituent for growth conditions at $25^{\circ} \mathrm{C}$ and a 3-hydroxyoctadecanoic acid substituent for growth conditions at $37^{\circ} \mathrm{C}$.

\section{Acknowledgments}

The authors thank the NCRR (1S10RR17262-01), NIAID (1U54AI57141-01), and NIEHS (P30ES07033) for generous funding and support. Additional thanks go to Professor František Tureček for helpful discussion and Thomas Kalhorn, Jace Jones, and Shawna Hengel for critical review of this manuscript. 


\section{References}

1. Ernst, R. K.; Guina, T.; Miller, S. I. Salmonella typhimurium Outer Membrane Remodeling: Role in Resistance to Host Innate Immunity. Microbes Infect. 2001, 3(14/15), 1327-1334.

2. Sajbidor, J. Effect of Some Environmental Factors on the Content and Composition of Microbial Membrane Lipids. Crit. Rev. Biotechnol. 1997, 17(2), 87-103

3. Suutari, M.; Laakso, S. Microbial Fatty Acids and Thermal Adaptation. Crit. Rev. Microbiol. 1994, 20(4), 285-328.

4. Raetz, C. R.; Whitfield, C. Lipopolysaccharide Endotoxins. Annu. Rev. Biochem. 2002, 71, 635-700.

5. Trent, M. S. Biosynthesis, Transport, and Modification of Lipid A. Biochem. Cell Biol. 2004, 82(1), 71-86.

6. Nikaido, H. Molecular Basis of Bacterial Outer Membrane Permeability Revisited. Microbiol. Mol. Biol. Rev. 2003, 67(4), 593-656.

7. Ernst, R. K. Guina, T.; Miller, S. I. How Intracellular Bacteria Survive: Surface Modifications that Promote Resistance to Host Innate Immune Responses. J. Infect. Dis. 1999, 179(Suppl.), 2S326-2S330.

8. Guo, L.; Lim, K. B.; Poduje, C. M.; Daniel, M.; Gunn, J. S.; Hackett, M.; Miller, S. Lipid A Acylation and Bacterial Resistance Against Vertebrate Antimicrobial Peptides. Cell 1998, 95(2), 189-198.

9. Miller, S. I.; Ernst, R. K.; Bader, M. W. LPS, TLR4, and Infectious Disease Diversity. Nat. Rev. Microbiol. 2005, 3(1), 36-46.

10. Rebeil, R.; Ernst, R. K.; Gowen, B. B.; Miller, S. I.; Hinnebusch, B. J. Variation in Lipid A Structure in the Pathogenic Tersiniae. Mol Microbiol. 2004, 52(5), 1363-1373.

11. McLendon, M. K.; Apicella, M. A.; Allen, L. A. Francisella tularensis: Taxonomy, Genetics, and Immunopathogenesis of a Potential Agent of Biowarfare. Annu. Rev. Microbiol. 2006, 60, 167-185.

12. Oyston, P. C.; Sjostedt, A.; Titball, R. W. Tularaemia: Bioterrorism Defence Renews Interest in Francisella tularensis. Nat. Rev. Microbiol. 2004, 2(12), 967-978.

13. Santic, M.; Molmeret, M.; Klose, K. E.; Abu Kwaik, Y. Francisella tularensis travels a novel, twisted road within macrophages. Trends Microbiol. 2006, 14(1), 37-44.

14. Ellis, J.; Oyston, P. C.; Green, M.; Titball, R. W. Tularemia. Clin Microbiol Rev. 2002, 15(4), 631-646.

15. Kieffer, T. L.; Cowley, S.; Nano, F. E.; Elkins, K. L. Francisella novicida LPS has Greater Immunobiological Activity in Mice than F. tularensis LPS and Contributes to F. novicida murine pathogenesis. Microbes Infect. 2003, 5(5), 397-403.

16. Phillips, N. J.; Schilling, B.; McLendon, M. K.; Apicella, M. A.; Gibson, B. W. Novel modification of lipid A of Francisella tularensis. Infect. Immun. 2004, 72(9), 5340-5348.

17. Vinogradov, E.; Perry M. B.; Conlan, J. W. Structural Analysis of Francisella tularensis lipopolysaccharide. Eur. J. Biochem. 2002, 269(24), 6112-6118.

18. Hajjar, A. M.; Harvey, M. D.; Shaffer, S. A.; Goodlett, D. R.; Sjostedt, A.; Edebro, H.; Forsman, M.; Bystrom, M.; Pelletier, M.; Wilson, C. B.; Miller, S. I.; Skerrett, S. J.; Ernst, R. K. Lack of in Vitro and in Vivo Recognition of Francisella tularensis Subspecies Lipopolysaccharide by Toll-Like Receptors. Infect. Immun. 2006, 74(12), 6730-6738.

19. Qureshi, N.; Takayama, K.; Heller, D.; Fenselau, C. Position of Ester Groups in the Lipid A Backbone of Lipopolysaccharides Obtained from Salmonella typhimurium. J. Biol. Chem. 1983, 258(21), 12947-12951.

20. Qureshi, N.; Takayama, K.; Ribi, E. Purification and Structural Determination of Nontoxic Lipid A Obtained from the Lipopolysaccharide of Salmonella typhimurium. J. Biol .Chem. 1982, 257(19), 11808-11815.

21. Seid, R. C., Jr.; Bone, W. M.; Phillips, L. R. Identification of Ester-Linked Fatty Acids of Bacterial Endotoxins by Negative Ion Fast Atom Bombardment Mass Spectrometry. Anal Biochem. 1986, 155(1), 168-176.

22. Takayama, K.; Qureshi, N.; Ribi, E.; Cantrell, J. L. Separation and Characterization of Toxic and Nontoxic Forms of Lipid A. Rev. Infect. Dis. 1984, 6(4), 439-443.

23. Guo, L.; Lim, K. B.; Gunn, J. S.; Bainbridge, B.; Darveau, R. P.; Hackett, M.; Miller, S. I. Regulation of Lipid A Modifications by Salmonella typhimurium Virulence Genes phoP-phoQ. Science 1997, 276(5310), 250 253.

24. Kaltashov, I. A.; Doroshenko, V.; Cotter, R. J.; Takayama, K.; Qureshi, N. Confirmation of the Structure of Lipid A Derived from the Lipopolysaccharide of Rhodobacter sphaeroides by a Combination of MALDI, LS
IMS, and Tandem Mass Spectrometry. Anal. Chem. 1997, 69(13), 2317-2322.

25. Lindner, B. Matrix-Assisted Laser Desorption/Ionization Time-ofFlight Mass Spectrometry of Lipopolysaccharides. Methods Mol. Biol. 2000, 145, 311-325.

26. Boue, S. M.; Cole, R. B. Confirmation of the Structure of Lipid A from Enterobacter agolomerans by Electrospray Ionization Tandem Mass Spectrometry. J. Mass Spectrom. 2000, 35(3), 361-368.

27. Chan, S.; Reinhold, V. N. Detailed Structural Characterization of Lipid A: Electrospray Ionization Coupled with Tandem Mass Spectrometry. Anal. Biochem. 1994, 218(1), 63-73.

28. Kussak, A.; Weintraub, A. Quadrupole Ion-Trap Mass Spectrometry to Locate Fatty Acids on Lipid A from Gram-Negative Bacteria. Anal. Biochem. 2002, 307(1), 131-137.

29. Sforza, S.; Silipo, A.; Molinaro, A.; Marchelli, R.; Parrilli, M.; Lanzetta, R Determination of Fatty Acid Positions in Native Lipid A by Positive and Negative Electrospray Ionization Mass Spectrometry. J. Mass Spectrom. 2004, 39(4), 378-383.

30. Douglas, D. J.; Frank, A. J.; Mao, D. Linear Ion Traps in Mass Spectrometry. Mass Spectrom. Rev. 2005, 24(1), 1-29.

31. March, R. An Introduction to Quadrupole Trap Mass Spectrometry. J. Mass Spectrom. 1997, 32, 351-369.

32. Schwartz, J. C.; Senko, M. W.; Syka, J. E. A Two-Dimensional Quadrupole Ion Trap Mass Spectrometer. J. Am. Soc. Mass Spectrom. 2002, 13(6), 659-669.

33. Battisti, J. M.; Sappington, K. N.; Smitherman, L. S.; Parrow, N. L.; Minnick, M. F. Environmental Signals Generate a Differential and Coordinated Expression of the Heme Receptor Gene Family of Bartonella quintana. Infect. Immun. 2006, 74(6), 3251-3261.

34. Hinnebusch, B. J. The Evolution of Flea-Borne Transmission in Yersinia pestis. Curr. Issues Mol. Biol. 2005, 7(2), 197-212.

35. Westphal, O.; Jann, K. Bacterial Lipopolysaccharides: Extraction with Phenol-Water and Further Applications of the Procedure. Methods Carbohydr. Chem. 1965, 5, 83-91.

36. Fischer, W.; Koch, H. U.; Haas, R. Improved Preparation of Lipoteichoic Acids. Eur. J. Biochem. 1983, 133(3), 523-530.

37. Caroff, M. Tacken, A. Szabo, L. Detergent-Accelerated Hydrolysis of Bacterial Endotoxins and Determination of the Anomeric Configuration of the Glycosyl Phosphate Present in the "Isolated Lipid A" Fragment of the Bordetella pertussis endotoxin. Carbohydr. Res. 1988, 175, 273-282.

38. Darveau, R. P.; Cunningham, M. D.; Bailey, T.; Seachord, C.; Ratcliffe, K.; Bainbridge, B.; Dietsch, M.; Page, R. C.; Aruffo, A. The Ability of Bacteria Associated with Chronic Inflammatory Disease to Stimulate E-Selectin Expression and Neutrophil Adhesion. Prog. Clin. Biol. Res. 1995, 392, 69-78.

39. Somerville, J. E. Jr.; Cassian, L.; Bainbridge, B.; Cunningham, M. D. Darveau, R. P. A Novel Escherichia coli Lipid A Mutant that Produces an Anti-Inflammatory Lipopolysaccharide. J. Clin. Invest. 1996, 97(2), 359365.

40. Hegarty, A.; O’Neill, P.; Rappoport, Z., ed.; In The Chemistry of Enols 1990; Wiley: Chichester, UK, p. 639.

41. Rappoport, Z.; Yamataka, H. Calculated Amide/Enol of Amide Energy Differences for Several Interesting Amide Systems. Chem. Commun. 2000, 21, 2101-2102.

42. Sklenak, S.; Apeloig, Y.; Rappoport, Z. Calculated pKEnol Values for Enols of Carboxylic Acid Derivatives $\mathrm{HC}=\mathrm{C}(\mathrm{OH}) \mathrm{X}, \mathrm{X}=\mathrm{OH}, \mathrm{NH} 2$ $\mathrm{NMe} 2, \mathrm{OMe}, \mathrm{OCHO}, \mathrm{F}, \mathrm{Cl}, \mathrm{Br} . J$. Am. Chem. Soc. 1998, 120, 10359-10364.

43. Gross, M. L. Charge-Remote Fragmentation: An Account of Research on Mechanisms and Applications. Int. J. Mass Spectrom. 2000, 200, 611-624.

44. Jensen, N.; Tomer, K.; Gross, M. Gas-Phase Ion Decomposition Occurring Remote to a Charged Site. J. Am. Chem. Soc. 1985, 107, 1863-1868.

45. Mole, T. Thermal Retro-Aldol Reaction. Chem. Ind. 1960, 1164-1165.

46. Costello, C. E.; Vath, J. E. Tandem Mass Spectrometry of Glycolipids. Methods Enzymol. 1990, 193, 738-768.

47. Domon, B.; Costello, C. E. A Systematic Nomenclature for Carbohydrate Fragmentations in FAB-MS/MS Spectra of Glycoconjugates. Glycoconjugate 1988, 5, 397-409.

48. Domon, B.; Vath, J. E.; Costello, C. E. Analysis of Derivatized Ceramides and Neutral Glycosphingolipids by High-Performance Tandem Mass Spectrometry. Anal. Biochem. 1990, 184(1), 151-164.

49. Koivusalo, M.; Haimi, P.; Heikinheimo, L.; Kostiainen, R.; Somerharju, P. Quantitative Determination of Phospholipid Compositions by ESIMS: Effects of Acyl Chain Length, Unsaturation, and Lipid Concentration on Instrument Response. J. Lipid Res. 2001, 42(4), 663-672. 